\title{
POSITIVE PERCEPTIONS OF BEER CONSUMPTION AMONG PORTUGUESE UNIVERSITY STUDENTS
}

\section{PERCEPCIONES POSITIVAS DEL CONSUMO DE CERVEZA ENTRE ESTUDIANTES UNIVERSITARIOS PORTUGUESES}

Joana R. Casanova', Margarida Gaspar Matos², María del Carmen Pérez-Fuentes ${ }^{3}$ \& Leandro S. Almeida

${ }^{1}$ Research Centre on Education (CIEd), Institute of Education, University of Minho. Portugal

${ }^{2}$ Faculty of Human Kinetics \& ISAMB, University of Lisbon. Portugal

${ }^{3}$ Faculty of Psychology, University of Almería. Spain

\section{Abstract}

The abusive consumption of alcohol by college students has negative effects on both individual and public health. Positive expectations about alcohol are related to behaviours and patterns of consumption frequently acquired in adolescence. Objective. This study analyses the impact of individual variables (gender, age at first drink, being away from home, and first option degree course) on beer consumption in first-year college students. The moderating effect of positive perceptions about alcohol consumption will also be considered. Method. The sample comprised 214 first-year college students at a Portuguese public university. Results. Positive perceptions of alcohol consumption had an impact on levels of beer consumption and the rate of beer consumption could be explained by just four student variables: age at first drink, gender, first option degree course, and positive perceptions of alcohol consumption. The indices of model fit were adequate. Conclusions. Interventions targeting reductions of student's alcohol consumption should consider the effects of positive perceptions of alcohol.

Keywords: Higher Education, alcohol consumption, consumption perceptions, first-year students.

\section{Resumen}

El consumo abusivo de alcohol por parte de estudiantes universitarios tiene efectos negativos tanto en la salud individual y pública. Las expectativas positivas sobre el alcohol están relacionadas con comportamientos y patrones de consumo frecuentemente adquiridos en la adolescencia. Objetivo. Este estudio analiza el impacto de las variables individuales (género, edad al primer trago, estar fuera de casa y primer curso de grado de opción) en el consumo de cerveza en estudiantes universitarios de primer año. También se considerará el efecto moderador de las percepciones positivas sobre el consumo de alcohol. Método. La muestra comprendió 214 estudiantes universitarios de primer año en una universidad pública portuguesa. Resultados. Las percepciones positivas del consumo de alcohol tuvieron un impacto en los niveles de consumo de cerveza y la tasa de consumo de cerveza podría explicarse por solo cuatro variables de los estudiantes: edad al primer trago, sexo, curso de primer grado y percepciones positivas del consumo de alcohol. Los índices de ajuste del modelo fueron adecuados. Conclusiones. Las intervenciones dirigidas a las reducciones en el consumo de alcohol de los estudiantes deben considerar los efectos de las percepciones positivas del alcohol.

Palabras clave: Ensenanza superior, consumo de alcohol, percepciones del consumo, alumnos de primer año. 
Alcohol consumption, in terms of the amount drunk, has been quite steady among young people over recent years. However, the consumption pattern has been changing, showing an increase in the consumption of spirits, concentrated drinking at weekends, and drinking more alcoholic drinks in a shorter period of time, or binge drinking, quite a new pattern of alcohol use (Feijão, 2016; Matos, Simões, Camacho, Reis \& Equipa Aventura Social, 2015; Matos et al., 2015). The JuNP study (Reis et al., 2017), an extension of the Health Behaviour in School aged Children (HBSC) study to University students, reported that $44.2 \%$ of university students had already tried alcohol and 38.3\% had already been drunk, with 14 years-old being the most commonly reported age for first getting drunk.

ESPAD (Feijão, 2016), another study specific to substance use carried out in 2015 included a survey of adolescents aged between 13 and 18. It reported that alcohol consumption in Portugal was $71.1 \%$ for lifetime, $61.5 \%$ in the last 12 months and $41.8 \%$ in the last 30 days (72.2\%, 61.8\% and $43.3 \%$ respectively in men and $70.1 \%$, $61.4 \%$ and $40.6 \%$ in women). Alcohol intake tended to increase with age, $30.7 \%$ reporting having drunk alcohol at some time by the age of 13 , rising to $91.1 \%$ at the age of 18. In terms of having drunk alcohol in the preceding 12 months, the rates ranged from $20.2 \%$ at the age of 13 , to $85.5 \%$ at the age of 18 . When reporting having drunk alcohol in the previous 30 days, the rates were $9.5 \%$ at the age of 13 , to $67.5 \%$ at the age of 18 . Across all age groups, boys reported drinking more alcohol except for drinking during the previous 30 days in 13 and 14-year olds, which was slightly higher in girls. Comparing alcohol intake in 2011 to results in 2015 alcohol intake tended to fall or stay the same.

In Portugal the 2014 HBSC study (Matos et al., 2015), which included adolescents with a mean age of 14 , revealed that $41.2 \%$ of the adolescents in $8^{\text {th }}$ and $10^{\text {th }}$ grade had already tried alcohol, 32.3\% had already drunk alcohol at some point in their lives, and $14.2 \%$ had drunk alcohol in the last 30 days. No gender differences were reported but there was a significant increase of alcohol use with age from 13 to 16 . Almost a fifth (17.2\%) reported having got drunk at least once, which also increased with age. The early age of alcohol consumption is a strong predictor of the occurrence of this consumption over the years (Davoren, Dahly, Shiely \& Perry, 2018). These frequent consumptions contribute to positive attitudes and expectations regarding alcohol consumption and to a minimized perception of its negative effects (Suárez, Del Moral, Martínez, John \& Musitu, 2016).

Looking at associated risks, the 2010 SSREU (Reis, Matos, Ramiro \& Equipa Aventura Social, 2011), another extension of HBSC to University students focused on sexual behaviour, reported that $35.5 \%$ of the students reported having had sex associated with alcohol intake, particularly men and especially related to short term relationships (less than 6 months), and on these situation using condoms less frequently (more health risks). Frequent consumption is also associated with later occurrence of psychopathological symptoms (Carbia, Corral, García-Moreno, Cadaveira \& Caamaño-Isorna, 2016).

A few decades ago, alcohol consumption was a gendered behaviour associated with men. However, this effect has been fading and there has been an increase in alcohol consumption in women and girls (Feijão, 2016; Inchley et al., 2016; Matos et al., 2015). Recent research about alcohol consumption and the reasons for it (Almeida, Casanova, Páramo, Reppold \& Rodríguez, 2020; Davoren, Cronin, Perry \& O'Connor, 2016; Kuntsche et al., 2015) identified a set of motivations related to alcohol intake that were associated with various determinants. Motives such as the search for pleasure and having fun, the avoidance of unpleasant emotions, overcoming social difficulties and complying with peer pressure, are four different motives needing different intervention approaches (Simões, Branquinho, Santos \& Gaspar de Matos, 2018; Wicki et al., 2017). Those motives correspond to different drinking patterns and lead to alcohol being consumed in different places and at different times, as well as to gender and age differences (Simões, Matos, Moreno, Rivera, Batista-Foguet \& Simons-Morton, 2012).

Positive perceptions about the effects of alcohol tend to be associated with higher consumption (Almeida, Casanova, Páramo, Reppold \& Rodríguez, 2020; Almeida et al., 2018). In addition, abusive alcohol consumption seems to be associated with impulsiveness or sensations seeking, as a response to negative emotions and the identification with behaviour that is culturally valued by peer groups (Schulte, Ramo \& Brown, 2009). Drinking patterns also affect alcohol intake, for example drinking slowly is associated with drinking less and engage in 
competitive drinking behaviors increases consumption (Ray, Stapleton, Turrisi \& Philion, 2012).

Parental support seems to have a protective effect, as does having a non-drinking leisure activity. In contrast, violence and family abuse, the presence of mental health problems and stressful life events are associated with increased consumption (Wlodarczyk, Schwarze, Rumpf, Metzner \& Pawils, 2017). Girls are more influenced by parental, sibling, and partner alcohol consumption, and they have more associated co-morbidities (mental health disorders such as depression and anxiety). They also tend to use alcohol as self-medication more often, although they seek treatment earlier than boys (Tyler, Stone \& Bersani, 2006).

Drinking with friends increases risks, whereas drinking with parents seems to have a protective effect (Reboussin, Song \& Wolfson, 2012). Parental monitoring and a good school connectedness decreases consumption, whereas participation in sports and leisure activities without parental support tends to increase alcohol use, violence, and injuries, mostly associated with sports "celebrations" and peer conflicts (Dever, Schulenberg, Dworkin, O'Malley, Kloska \& Bachman, 2012; Matos, 2013). Because higher education is often the first time many students leave home, this separation from parents can increase alcohol consumption patterns as students adjust during their first weeks at university (Zurita, Chacón, Castro, Martínez, Espejo, Knox \& Muros, 2018). Some studies relate the alcohol consumption with difficulties in the adaptation to university, distance from the family, lack of social support or with the experience of new responsibilities. In these situations, the consumption can be perceived as facilitating new social interactions and meet new friends, overcoming loneliness and depressive symptoms (Costa, Martins, Proença \& Silva, 2017; Davoren et al., 2018; Schnetzer, Schulenberg \& Buchanan, 2013). Students with negative perceptions concerning alcohol consumption tend to assume a protective behavior, avoiding drinking, and students with more positive perceptions have greater tolerance to attitudes and practices about alcohol consumption (Merrill, Kenney \& Barnett, 2017).

This study analyses the impact of personal variables (gender, age at first drink, being away from home, and first-choice degree course) on beer consumption in firstyear university students. This analysis assumes a moderating effect of students' positive perceptions about alcohol consumption on levels of beer consumption.

\section{METHOD}

\section{Participants}

The convenience sample included 214 first-year students aged between 17 and 42, with a mean of 18.49 $(S D=2.56)$, at a public university in the North of Portugal. Almost three quarters of the sample (71.0\%) were female students. The students were studying in the following areas: Science (4.2\%), Economics and Management (28.0\%), Engineering (30.8\%), Social Sciences (20.1\%), and Education (16.4\%). Due of numerus clausus system to access higher education in Portugal, based in national examinations and classifications in secondary schools, the majority of students (53.7\%) were not studying their first choice of degree, and most came from families with low levels of educational qualifications (only $12.9 \%$ of fathers and $15.0 \%$ of mothers had degree level qualifications). The majority of the students (63.4\%) do not leave home residence to attend university.

\section{Instruments}

We used a brief version of the Alcohol ExpectancyAdolescent Questionnaire (AEQ; (AEQ; Brown, Christiansen \& Goldman, 1987). This version includes five items about positive perceptions of alcohol consumption, following a Portuguese validation (Almeida, PérezFuientes, Casanova, Gázquez \& Molero, 2018) based on Spanish version (Gázquez et al., 2015). The students completed the items on a five-point Likert scale ranging from 1 (strongly disagree) to 5 (strongly agree). Previous study confirmed the unidimensionality of the positive perception items, and reliability with Cronbach's alpha and omega was .79 and .83, respectively (Almeida et al., 2018).

We used a socio-demographic questionnaire to gather general personal information (age, gender), academic information (area of study, first option degree course) and information about alcohol consumption (age at first drink, and frequency of beer consumption: from 1Never to 5-Daily). To obtain a standard rate of consumption for all sample, beer was used as indicator of students' consumption. In some previous interviews, 
beer was largely identified as the drink more frequent and generalized among HE students and specifically at the institution where this study occurred.

\section{Procedure}

The study was conducted in accordance with the ethical standards, 1964 Helsinki declaration and its later amendments or comparable ethical standards and with permission of University Research Ethics committee. Questionnaires have been applied in classroom context with the professor's consent, ten minutes after a class. All participants were informed about the contents and objectives of this study, as well as the confidentiality of the data and filled in the required informed participation consent form.

\section{Data Analysis}

Collected data were statistically analyzed through Structural Equation Modeling (SEM; Kline, 2016) to test the interactions and impact of variables in alcohol consumption. The causal model was evaluated with the recommended goodness-of-fit indices (Marôco, 2014): $\chi 2 / d f, C F I, G F I$, and RMSEA. The models were considered have a good fit when RMSEA values were below .08 and $C F /$ and GF/values were above .9. The local goodness-offit was accessed through standardized factor weights and with individual item reliability. The causal trajectories were considered to be significant when $p<.05$.

\section{RESULTS}

Table 1 presents the results of the descriptive statistics for the different variables age, gender, first option degree course, age at first drink, and frequency of beer drinking and positive perceptions of alcohol consumption.

The average age of consumption of the participants is lower than the age of entry into $\operatorname{HE}(M=15.83, S D=$ 1.29), with some students with a very early age of experimentation, 10 years old. There are also students who the age of first consumption was 20 years, suggesting only alcohol consumption after entering $\mathrm{HE}$. Despite the early age of alcohol consumption, the frequency of alcohol consumption is not more than 1-2 times a month, but may suggest drinking more alcoholic drinks at one moment (binge drinking).
Considering the punctuations of students in the items of positive perceptions of alcohol consumption, the range were 5 to 21 points $(M=12.68, S D=3.68)$, below the intermediate value of the scale. The values suggest low levels of positive perceptions. More agreement concerns perception that alcohol makes a person feel strong (item $4, M=2.99, S D=1.12$ ), relaxed (item $5, M=$ $2.88, S D=1.12$ ) and happy (item $1, M=2.73, S D=1.02$ ). The perception that alcohol can help to think better (item $2, M=1.74, S D=.71$ ) receives more disagreement among students, and this is also the item with less variability of responses suggesting majority of students disagree.

Table 1. Descriptive statistics

\begin{tabular}{|c|c|c|c|c|c|c|}
\hline Variable & $M$ & $S D$ & Min & Max & Sk & $\mathrm{ku}$ \\
\hline Age at first drink & 15.83 & 1.29 & 10 & 20 & -.59 & 2.55 \\
\hline $\begin{array}{l}\text { Frequency of beer } \\
\text { drinking }\end{array}$ & 2.11 & 1.02 & 1 & 5 & .53 & -.74 \\
\hline Positive Perceptions & 12.68 & 3.68 & 5 & 21 & -.53 & -.31 \\
\hline $\begin{array}{l}\text { It } 1 \text { - Alcohol generally } \\
\text { has powerful positive } \\
\text { effects on people } \\
\text { (makes a person feel } \\
\text { good or happy; future } \\
\text { seems brighter). }\end{array}$ & 2.73 & 1.02 & 1 & 5 & -.00 & -.42 \\
\hline $\begin{array}{l}\text { It } 2 \text { - Alcohol helps } \\
\text { people think better and } \\
\text { helps coordination } \\
\text { (people understand } \\
\text { things better; can do } \\
\text { things better). }\end{array}$ & 1.74 & .71 & 1 & 5 & .57 & -.24 \\
\hline $\begin{array}{l}\text { It } 3 \text { - Alcohol improves } \\
\text { sex (more enjoyable; } \\
\text { feel more romantic or } \\
\text { sexual; makes it easier } \\
\text { to have sex). }\end{array}$ & 2.34 & .90 & 1 & 5 & -.31 & -.91 \\
\hline $\begin{array}{l}\text { It4 - Alcohol makes a } \\
\text { person feel stronger } \\
\text { and more powerful } \\
\text { (easier to fight, speak in } \\
\text { front of others, stand } \\
\text { up to others). }\end{array}$ & 2.99 & 1.12 & 1 & 5 & -.31 & -.61 \\
\hline $\begin{array}{l}\text { It5 - Alcohol helps a } \\
\text { person relax, feel less } \\
\text { tense, and can keep a } \\
\text { person's mind off of } \\
\text { mistakes at school or } \\
\text { work. }\end{array}$ & 2.88 & 1.12 & 1 & 5 & -.27 & -.74 \\
\hline
\end{tabular}

Figure 1 shows the relationships between the variables, with beer consumption as the dependent variable. We tested the unidimensionality of the items in the short version of positive perceptions and the five items present loadings range from .51 to .77 in a latent variable defined as positive perceptions of alcohol consumption, meaning the scale is unidimensional. The 
SEM model demonstrated good fit $(\chi 2=47.552, p=.001$, $\chi 2 / d f=2.264, \mathrm{CFI}=.939, \mathrm{GFI}=.953, \mathrm{RMSEA}=.077[.048-$
.106], and accounts for $36 \%$ of the variance in the frequency of beer consumption.

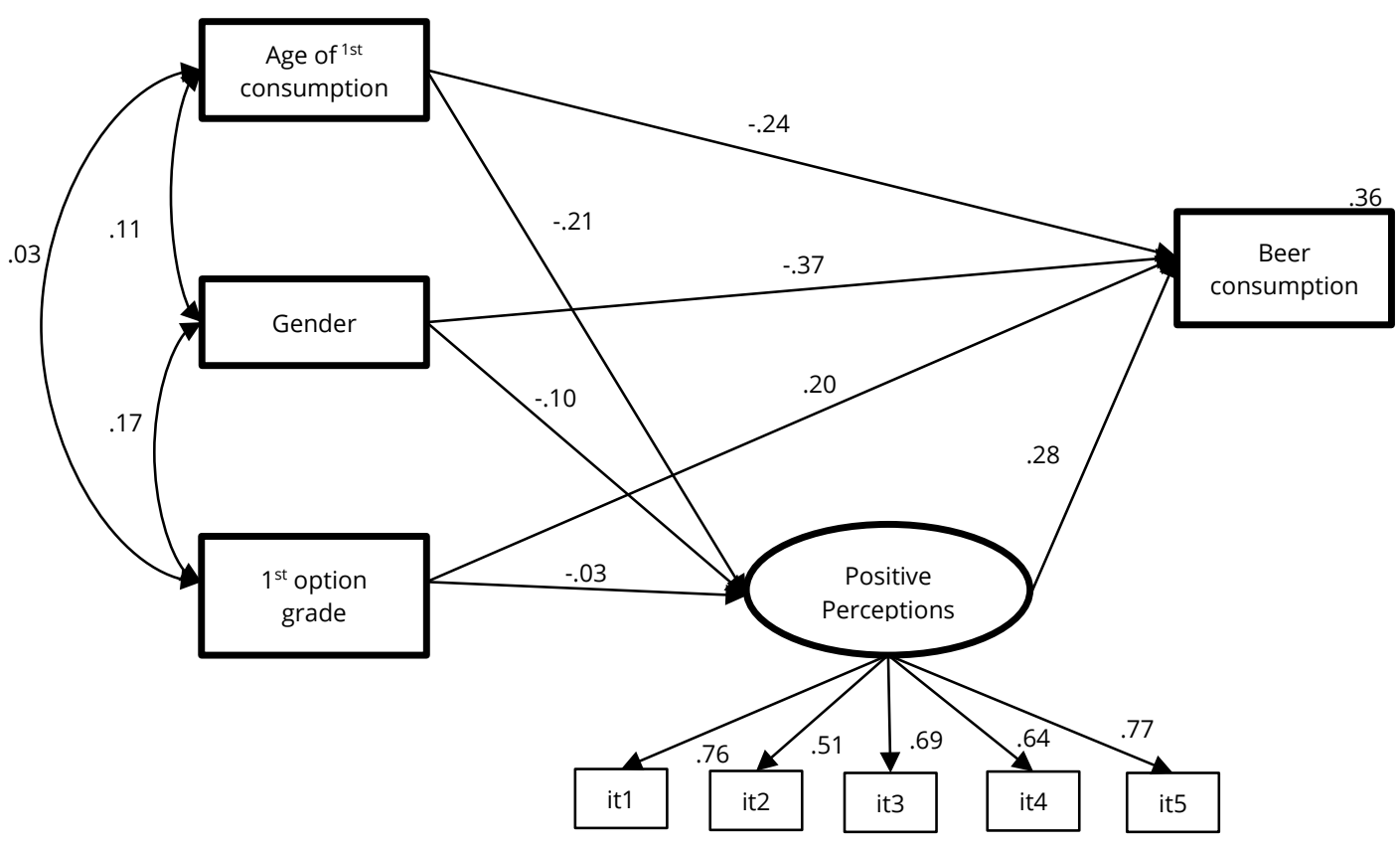

Figure 1. Model of beer consumption in first-year students

The model shows the direct impacts of age at first drink, gender, and first choice degree course on positive perceptions and on the frequency of beer consumption. Seeing the data, the first-choice degree courses isn't related to positive perceptions. Significant relation exists taking students' gender and age. Results show male students present higher positive perceptions about alcohol consumption and the age at first drink as a negative impact on positive perceptions, that means early consumption is related to more positive perceptions.

Concerning the impact of those personal variables in alcohol consumption, gender has a significant effect traducing male students had a higher rate of beer consumption. The effects of age at first drink, and being on the first choice of degree course increase when we consider indirect effects via positive perceptions. Beginning drinking at an earlier age is positively related to the frequency of beer consumption. Students who are not on their first-choice degree course exhibited higher levels of beer consumption. Finally, positive perceptions about alcohol consumption have a positive impact on levels of beer consumption.

\section{DISCUSSION}

Results in this study confirm good psychometrics indices in terms of internal validity of items of "Positive perceptions of alcohol consumption", as initial studies of validation to Portuguese Higher Education students (Almeida et al., 2018). As expected, all five items loading above .50 in the latent construct defined as positive perception of consumption. This consistency on data validity allows us to consider the overall score as an effective measure of positive perceptions of alcohol consumption in future research to analyze students' academic experiences on topic.

In this sample, taking global score and each item of the scale the data don't present high level of positive perceptions concerning alcohol consumption. Also in general students say to drink no more than two or three times per month, even we know some times the amount of drinks is high, being the phenomenon of binge drinking relatively frequent among college students (Feijão, 2016; Matos et al., 2015). Positive perceptions on alcohol consumption is related to gender (more positive perceptions in male students) and to the age at first drink (more positive perceptions in those who started drinking 
younger). In the literature, gender and age at first drink have tended to be assumed to be positively related to motivation to consume (Davoren et al., 2018). Perceptions about alcohol consumption were not related to the fact that students were or were not on their firstchoice degree course (almost $50 \%$ of students are not in first option course due to the numerus clausus system regulating access to higher education).

The direct impact of these three variables (age at first drink, gender, and first-choice degree course) on levels of alcohol (beer) consumption was significant. There was a higher rate of consumption in male students. The effects of age at first drink and being on the firstchoice degree course were stronger when the indirect effects of positive perceptions were considered. As in previous studies (Almeida et al., 2018; Davoren et al., 2016), older students and those who started drinking alcohol younger reported higher beer consumption. Students not on their first-choice degree course also reported higher levels of beer consumption. No being in a degree of first option can produces less engagement in learning and other academic activities with more participation in social and interpersonal events out campus, namely during night, where the alcohol consumption increases. Not be in a course of first option can increase the alcohol consumption to reduce unpleasant emotions, low perceptions of self-efficacy and meet social support (Almeida et al., 2018; Simões et al., 2018; Wicki et al., 2017). Students not placed in a first option course tend to present more difficulties in their academic adaptation, what appears related to high alcohol consumptions rates (Costa et al., 2017; Davoren et al., 2018).

This constellation of variables and interactions confirm that alcohol consumption in adolescents and young adults is a complex and multivariate phenomenon (Almeida et al., 2018; Davoren et al., 2016; Kuntsche et al., 2015). In this sample of first-year Portuguese university students, positive perceptions about alcohol consumption had an impact on the levels of beer consumption. Students who believed in the benefits of alcohol consumption in the social aspects of their academic lives tended to drink more beer weekly or daily. Over a third (36\%) of the variance in the rate of beer consumption could be explained by the variables considered in this study, and particularly by the effect of positive perceptions of alcohol consumption as in literature (Almeida et al., 2018; Merrill et al., 2017; Schulte et al., 2009).

\section{Conclusions}

Alcohol consumption appears today as health problem of a large number of university students. Its impact on academic engagement and achievement is relevant, being necessary better understanding about reasons or motives for those high rates of consumption. In this study with Portuguese first-year students, a combination of personal variables assumes relevance in explanation of alcohol consumption. Among those variables, the positive perceptions about alcohol assumes particular impact. Some students having troubles in their adaptation to university can deliberately see in alcohol a strategy to cope with their problems of depression, anxiety and loneliness.

In order to reduce alcohol consumption in university students, particularly first-year students, it is important to consider their perceptions about the possible positive effects of alcohol in university social events. Immediate gains in interpersonal acceptance and helping one relax can be excuses for increased consumption. These positive perceptions tend to raise the level of consumption in students who are not on their first-choice degree course and who had an early introduction to drinking alcohol.

Health promotion interventions must be tailored to the motives for drinking. Those who do not drink for positive reasons, but instead report drinking to avoid negative emotions and self-perceptions could also be targets for student counselling services. Overall, universal prevention programs could consider population-level action targeting students' wellbeing, conviviality, and selfconfidence in alcohol-free settings. This is also a strong message for public policies aimed at controlling alcohol use by young people.

There are some limitations that should be noted. Firstly, this study used convenience sampling and a small number of participants. In addition, the sample was via students in classes. In the future, it would be useful to include students in other academic contexts, for example, in university social activities where more alcohol tends to be consumed. Other alcoholic drinks besides beer should also be included to determine the level of consumption. 


\section{Conflict of interest}

The authors have no conflicts of interest to declare.

\section{Funding}

This work is funded by CIEd - Research Centre on Education, Institute of Education, University of Minho, projects UIDB/01661/2020 and UIDP/01661/2020, through national funds of FCT/MCTES-PT. Joana $R$. Casanova received funding from the Portuguese Foundation for Science and Technology (FCT) as a Doctoral Grant, under grant agreement number SFRH/BD/117902/2016

\section{REFERENCES}

Almeida, L. S., Casanova, J. R., Páramo, M. F., Reppold, C., \& Rodríguez, M. S. (2020). Estudos de validade da Escala de Percepções Positivas e Negativas sobre Efeitos do Álcool. Revista de Saúde Pública, 54. doi:10.11606/s1518-8787.2020054001811

Almeida, L. S., Pérez Fuentes, M. del C., Casanova, J. R., Gázquez, J. J., \& Molero, M. del M. (2018). Alcohol Expectancy-Adolescent Questionnaire (AEQ-AB): Validation for portuguese college students. Health and Addictions/Salud y Drogas, 18(2), 155-163. doi:10.21134/haaj.v18i2.389

Brown, S. A., Christiansen, B. A., \& Goldman, M. S. (1987). The Alcohol Expectancy Questionnaire: An instrument for the assessment of adolescent and adult alcohol expectancies. Journal of Studies on A/cohol, 48(5), 483-491. doi:10.15288/jsa.1987.48.483

Carbia, C., Corral, M., García-Moreno, L. M., Cadaveira, F., \& CaamañoIsorna, F. (2016). Early alcohol use and psychopathological symptoms in university students. Psicothema, 28(3), 247-252. doi:10.7334/psicothema2015.251

Costa, M. B., Martins, M. J. D., Proença, A. J., \& Silva, A. M. (2017). Beliefs and attitudes of higher education students associated with the use of psychoactive substances. Psychologica, 1(60), 19-37. doi :10.14195/1647-8606_60-1_2

Davoren, M. P., Cronin, M., Perry, I. J., \& O'Connor, K. (2016). Alcohol consumption among university students: A typology of consumption to aid the tailoring of effective public health policy. BMJ Open, 6(11). doi:10.1136/bmjopen-2016-011815

Davoren, M. P., Dahly, D., Shiely, F., \& Perry, I. J. (2018). Alcohol consumption among university students: A latent class analysis. Drugs: Education, Prevention and Policy, 25(5), 422-430. doi:10.1080/09687637.2017.1290787

Dever, B. V., Schulenberg, J. E., Dworkin, J. B., O’Malley, P. M., Kloska, D. D., \& Bachman, J. G. (2012). Predicting risk-taking with and without substance use: The effects of parental monitoring, school bonding, and sports participation. Prevention Science, 13(6), 605-615. doi:10.1007/s11121-012-0288-z
Feijão, F. (2016). European school survey project in alcohol and others drugs: Portugal/2015. Estudo sobre o consumo de alcool, tabaco, droga e outros comportamentos aditivos e dependências ECATD. CAD/2015.

Gázquez, J. J., Pérez-Fuentes, M. C., Molero, M., Martos, Á., Cardila, F., Barragán, A. B., Carrión, J. J., Garzón, A., \& Mercader, I. (2015). Adaptación Española del Cuestionario de Expectativas del Alcohol en Adolescentes, versión breve. European Journal of Investigation in Health, Psychology and Education, 5(3), 357-369. doi:10.1989/ejihpe.v5i3.138

Inchley, J., Currie, D., Young, T., O., S., T., T., \& (Eds.)., et al. (2016). Growing up unequal: Gender and socioeconomic differences in young people's health and well-being. Health behaviour in school-aged children (HBSC) study: International Report from the 2013/2014 survey.

Kline, R. B. (2016). Principles and practice of structural equation modelling (4th ed.). The Guildford Press.

Kuntsche, E., Wicki, M., Windlin, B., Roberts, C., Gabhainn, S. N., Van Der Sluijs, W., Aasvee, K., Gaspar De Matos, M., Dankulincová, Z., Hublet, A., Tynjälä, J., Välimaa, R., Bendtsen, P., Vieno, A., Mazur, J., Farkas, J., \& Demetrovics, Z. (2015). Drinking motives mediate cultural differences but not gender differences in adolescent alcohol use. Journal of Adolescent Health, 56(3), 323-329. doi:10.1016/j.jadohealth.2014.10.267

Marôco, J. (2014). Análise de equações estruturais: Fundamentos teóricos, software \& aplicações (2nd ed.). ReportNumber.

Matos, M. G. (2013). Does physical activity promotion advantages need the identification of associated health compromising features such as injuries, alcohol use and interpersonal violence? Highlights from HBSC/ WHO Portuguese Survey. Journal of Child and Adolescent Behaviour, 01(03), 1-6. doi:10.4172/2375-4494.1000113

Matos, M. G., Reis, M., Camacho, I., Simões, C., Gomez-Baya, D., Mota, C., Tomé, G., Gaspar, T., Machado, M. do C., \& Equipa Aventura Social. (2015). Em tempo de recessão, os adolescentes portugueses continuam saudáveis e felizes ou são ainda saudáveis mas já não felizes? Arquivos de Medicina, 116-122.

Matos, M. G., Simões, C., Camacho, I., Reis, M., \& Equipa Aventura Social. (2015). A saúde dos adolescentes portugueses em tempos de recessão - Dados nacionais do estudo HBSC de 2014

Merrill, J. E., Kenney, S. R., \& Barnett, N. P. (2017). A time-varying effect model of the dynamic association between alcohol use and consequences over the first two years of college. Physiology \& Behavior, 73, 57-62. doi:10.1016/j.addbeh.2017.04.022

Ray, A. E., Stapleton, J. L., Turrisi, R., \& Philion, E. (2012). Patterns of drinking-related protective and risk behaviors in college student drinkers. Addictive Behaviors, 374), 449-455. doi:10.1016/j.addbeh.2011.12.005

Reboussin, B. A., Song, E.-Y., \& Wolfson, M. (2012). Social influences on the clustering of underage risky drinking and its consequences in communities. Journal of Studies on Alcohol and Drugs, 73(6), 890898. doi:10.15288/jsad.2012.73.890 
Reis, M., Matos, M. G. de, \& Equipa Aventura Social. (2017). Comportamentos de Saúde dos Jovens Universitários Portugueses - Dados Nacionais JuNP 2016 - Relatório de Estudo.

Reis, M., Matos, M. G., Ramiro, L., \& Equipa Aventura Social. (2011). Saúde sexual e reprodutiva dos estudantes do Ensino Superior. Relatório do Estudo - Dados Nacionais SSREU 2010. In Dados.

Schnetzer, L. W., Schulenberg, S. E., \& Buchanan, E. M. (2013). Differential associations among alcohol use, depression and perceived life meaning in male and female college students. Journal of Substance Use, 18(4), 311-319. doi:10.3109/14659891.2012.661026

Schulte, M. T., Ramo, D., \& Brown, S. A. (2009). Gender differences in factors influencing alcohol use and drinking progression among adolescents. Clinical Psychology Review, 296), 535-547. doi:10.1016/j.cpr.2009.06.003

Simões, C., Branquinho, C., Santos, A., \& Gaspar de Matos, M. (2018). Motives to use alcohol among adolescents according to their neighbourhood characteristics, gender, age, and drinking patterns. Journal of Substance Use, 23(1), 43-48. doi:10.1080/14659891.2017.1348550

Simões, C., Matos, M. G., Moreno, C., Rivera, F., Batista-Foguet, J. M., \& Simons-Morton, B. (2012). Substance use in Portuguese and Spanish adolescents: Highlights from differences, similarities and moderating effects. The Spanish Journal of Psychology, 15(3), 10241037. doi:10.5209/rev SJOP.2012.v15.n3.39393

Suárez, C., Del Moral, G., Martínez, B., John, B., \& Musitu, G. (2016). El patrón de consumo de alcohol en adultos desde la perspectiva de los adolescentes. Gaceta Sanitaria, 3a1), 11-17. doi:10.1016/j.gaceta.2015.06.004

Tyler, K. A., Stone, R. T., \& Bersani, B. (2006). Examining the changing influence of predictors on adolescent alcohol misuse. Journal of Child \& Adolescent Substance Abuse, 16(2), 95-114. doi:10.1300/J029v16n02

Wicki, M., Kuntsche, E., Eichenberger, Y., Aasvee, K., Bendtsen, P., Dankulincová Veselská, Z., Demetrovics, Z., Dzielska, A., Farkas, J., de Matos, M. G., Roberts, C., Tynjälä, J., Välimaa, R., \& Vieno, A. (2017). Different drinking motives, different adverse consequences? Evidence among adolescents from 10 European countries. Drug and Alcohol Review, 36(6), 731-741. doi:10.1111/dar.12572

Wlodarczyk, O., Schwarze, M., Rumpf, H. J., Metzner, F., \& Pawils, S. (2017). Protective mental health factors in children of parents with alcohol and drug use disorders: A systematic review. PLOS ONE, 12(6), 1-15. doi:10.1371/journal.pone.0179140

Zurita, F., Chacón, R., Castro, M., Martínez, A., Espejo, T., Knox, E., \& Muros, J. J. (2018). Problematic consumption of substances and video game use in Spanish university students depending on sex and place of residence. Health and Addictions/Salud y Drogas, 18(1), 89-96. doi:10.21134/haaj.v18i1.350 